\title{
Enhanced Thalamocortical Synaptic Transmission and Dysregulation of the Excitatory-Inhibitory Balance at the Thalamocortical Feedforward Inhibitory Microcircuit in a Genetic Mouse Model of Migraine
}

\author{
Angelita Tottene, ${ }^{1}$ Morgana Favero, ${ }^{2}$ and Daniela Pietrobon ${ }^{1,3}$ \\ ${ }^{1}$ Department of Biomedical Sciences, University of Padova, 35131 Padova, Italy, ${ }^{2}$ Department of Neuroscience, Biomedicine and Movement Sciences, \\ University of Verona, 37129 Verona, Italy, and ${ }^{3}$ Padova Neuroscience Center, University of Padova, and CNR Institute of Neuroscience, 35131 Padova, Italy
}

\begin{abstract}
Migraine is a complex brain disorder, characterized by attacks of unilateral headache and global dysfunction in multisensory information processing, whose underlying cellular and circuit mechanisms remain unknown. The finding of enhanced excitatory, but unaltered inhibitory, neurotransmission at intracortical synapses in mouse models of familial hemiplegic migraine (FHM) suggested the hypothesis that dysregulation of the excitatory-inhibitory balance in specific circuits is a key pathogenic mechanism. Here, we investigated the thalamocortical (TC) feedforward inhibitory microcircuit in FHM1 mice of both sexes carrying a gain-of-function mutation in $\mathrm{Ca}_{\mathrm{V}}$ 2.1. We show that TC synaptic transmission in somatosensory cortex is enhanced in FHM1 mice. Due to similar gain of function of TC excitation of layer 4 excitatory and fast-spiking inhibitory neurons elicited by single thalamic stimulations, neither the excitatory-inhibitory balance nor the integration time window set by the TC feedforward inhibitory microcircuit was altered in FHM1 mice. However, during repetitive thalamic stimulation, the typical shift of the excitatory-inhibitory balance toward excitation and the widening of the integration time window were both smaller in FHM1 compared with WT mice, revealing a dysregulation of the excitatory-inhibitory balance, whereby the balance is relatively skewed toward inhibition. This is due to an unexpected differential effect of the FHM1 mutation on short-term synaptic plasticity at TC synapses on cortical excitatory and fast-spiking inhibitory neurons. Our findings point to enhanced transmission of sensory, including trigeminovascular nociceptive, signals from thalamic nuclei to cortex and TC excitatory-inhibitory imbalance as mechanisms that may contribute to headache, increased sensory gain, and sensory processing dysfunctions in migraine.
\end{abstract}

Key words: barrel cortex; calcium channel; excitatory-inhibitory; migraine; synaptic transmission; thalamocortical

Significance Statement

Migraine is a complex brain disorder, characterized by attacks of unilateral headache and by global dysfunction in multisensory information processing, whose underlying cellular and circuit mechanisms remain unknown. Here we provide insights into these mechanisms by investigating thalamocortical (TC) synaptic transmission and the function of the TC feedforward inhibitory microcircuit in a mouse model of a rare monogenic migraine. This microcircuit is critical for gating information flow to cortex and for sensory processing. We reveal increased TC transmission and dysregulation of the cortical excitatory-inhibitory balance set by the TC feedforward inhibitory microcircuit, whereby the balance is relatively skewed toward inhibition during repetitive thalamic activity. These alterations may contribute to headache, increased sensory gain, and sensory processing dysfunctions in migraine.

\section{Introduction}

Migraine is a remarkably common, disabling, and costly brain disorder, characterized by a global dysfunction in multisensory

The authors declare no competing financial interests. information processing and integration and by attacks of typically throbbing, unilateral headache with certain associated features, such as nausea and amplification of percepts from multiple senses (Pietrobon and Moskowitz, 2013; Schwedt et al., 2015; Goadsby et al., 2017; Brennan and Pietrobon, 2018). In one-third of patients, migraine pain is preceded by transient sensory distur-

Correspondence should be addressed to Daniela Pietrobon at daniela.pietrobon@unipd.it.

https://doi.org/10.1523/JNEUROSCI.1840-19.2019

Copyright $\odot 2019$ the authors 
bances (aura), whose neurophysiological correlate is cortical spreading depression (CSD), a cortical wave of neuronal depolarization (Pietrobon and Moskowitz, 2014), which may also trigger the headache mechanisms (Burstein et al., 2015; Filiz et al., 2019). The neurobiological mechanisms of the primary brain dysfunctions underlying the onset of a migraine attack, susceptibility to CSD, and the global dysfunction in multisensory information processing remain largely unknown.

Knock-in mouse models of familial hemiplegic migraine (FHM, a monogenic subtype of migraine with aura) show increased susceptibility to experimentally induced CSD (van den Maagdenberg et al., 2004; Leo et al., 2011) and provide a unique experimental system to study the cellular and circuit mechanisms of the primary brain dysfunctions causing a migraine disorder (Pietrobon and Brennan, 2019). FHM type 1 (FHM1) knock-in mice carry gain-of-function mutations in the $\mathrm{Ca}_{\mathrm{V}} 2.1$ channel, which plays a dominant role in neurotransmitter release at many brain synapses (van den Maagdenberg et al., 2004; Pietrobon, 2013). Excitatory synaptic transmission at several intracortical pyramidal cell synapses is enhanced in FHM1 mice; in striking contrast, inhibitory synaptic transmission at fast-spiking (FS) and other interneuron synapses is unaltered (Tottene et al., 2009; Vecchia et al., 2014; Marchionni, Pilati, Pietrobon, unpublished observations).

Due to the differential effect of FHM1 mutations on excitatory and inhibitory synaptic transmission, the cortical core microcircuits mediating feedback and feedforward inhibition, which dynamically maintain the excitatory-inhibitory balance necessary for the transfer of information while preventing runaway excitation (Isaacson and Scanziani, 2011; Tremblay et al., 2016), are likely dysfunctional in FHM1 (Pietrobon, 2018). This suggests the hypothesis that impaired regulation of the excitatory-inhibitory balance in specific circuits in the cerebral cortex (and other brain structures) may be a primary brain dysfunction in FHM and possibly migraine (Vecchia and Pietrobon, 2012; Pietrobon and Brennan, 2019). Insights into the type of excitatory-inhibitory imbalance that may favor CSD ignition in migraine are provided by the evidence that the increased susceptibility to experimental CSD in the FHM mouse models is largely due to excessive cortical glutamatergic synaptic transmission, arising from either increased glutamate release (FHM1) (Tottene et al., 2009) or impaired glutamate clearance (FHM type 2) (Capuani et al., 2016). However, the specific neuronal circuits whose dysfunctional regulation creates the conditions for ignition of "spontaneous" CSDs and, in general, for precipitation of the migraine attack by specific triggers, and may underlie the interictal alterations in sensory processing are unknown. On a more basic level, also unknown is how the FHM mutations alter the core microcircuits essential for the correct processing of sensory information and to prevent overexcitation.

Here, we investigated the effect of a FHM1 mutation on a key feedforward inhibitory (FFI) microcircuit, the thalamocortical (TC) microcircuit resulting from the divergence of TC axons onto layer 4 (L4) regular spiking (RS) principal neurons and L4 FS interneurons, making inhibitory synapses onto RS neurons. This microcircuit is very interesting to study in the context of migraine because it is critical in gating information flow to the cortex (including trigeminovascular nociceptive information) and in coordinating excitation and inhibition in the initial phases of cortical sensory processing. It controls the time window for integration of thalamic inputs and, hence, the temporal precision of cortical sensory responses; it participates in sensory gain modulation and effectively "shunts" cortical recurrent excitation, thus preventing overexcitation and preserving discrete signaling in cortical networks (Sun et al., 2006; Isaacson and Scanziani, 2011; Tremblay et al., 2016). Other important features of sensory processing modulated by the TC FFI microcircuit include the spatial focusing of cortical sensory responses, the dynamic range, the rapid sensory adaptation, and the adaptation-dependent trade-off between detectability and discriminability (Moore, 2004; Bruno, 2011; Isaacson and Scanziani, 2011; Tremblay et al., 2016; Whitmire and Stanley, 2016).

We show that TC synaptic transmission is enhanced in FHM1 knock-in mice, and reveal a dysregulation of the excitatory-inhibitory balance set by the TC FFI microcircuit in L4 RS neurons of somatosensory cortex, whereby the balance is relatively skewed toward inhibition during repetitive thalamic stimulation as a consequence of a differential effect of the FHM1 mutation on short-term synaptic plasticity at the TC synapses on L4 RS and FS neurons.

\section{Materials and Methods}

Animals. Experiments were performed using WT C57BL6J mice and homozygous knock-in mice carrying the $\mathrm{Ca}_{\mathrm{V}} 2.1 \mathrm{R} 192 \mathrm{Q}$ FHM1 mutation with the same genetic background (van den Maagdenberg et al., 2004). Animals were housed in specific pathogen-free conditions, maintained on a $12 \mathrm{~h}$ light/dark cycle, with free access to food and water. All experimental procedures involving animals and their care were performed in accordance with National laws and policies (D.L. 26, March 14, 2014) and with the guidelines established by the European Community Council Directive (2010/63/UE), and were approved by the local authority veterinary services (AUT. MIN. 652/2015-PR).

Slices. Acute TC slices of the barrel cortex were prepared from P16-P19 mice of either sex as described by Tottene et al. (2009). Briefly, animals were anesthetized with isoflurane and decapitated. The brain was quickly removed and dissected at the right angles to obtain TC slices, as described by Agmon and Connors (1991); 400- $\mu$ m-thick slices were then cut on the vibratome (Leica Microsystems, VT 1200S) in an ice-cold cutting solution (in mM as follows: $130 \mathrm{~K}$ gluconate, $15 \mathrm{KCl}$, 0.2 EGTA, 20 HEPES, 25 glucose, 2 kynurenic acid, 0.05 minocycline, $\mathrm{pH} 7.4$ with $5 \% \mathrm{CO}_{2}$ ) (Dugué et al., 2005). Slices were transferred for $1 \mathrm{~min}$ in a $95 \% \mathrm{O}_{2} / 5 \%$ $\mathrm{CO}_{2}$ saturated solution containing (in mM as follows: $225 \mathrm{D}-$ mannitol, 2.5 $\mathrm{KCl}, 1.25 \mathrm{NaH}_{2} \mathrm{PO}_{4}, 26 \mathrm{NaHCO}_{3}, 25$ glucose, $0.8 \mathrm{CaCl}_{2}, 8 \mathrm{MgCl}_{2}, 2$ kynurenic acid, 0.05 minocycline), then in standard ACSF plus $50 \mathrm{~nm}$ minocycline at $30^{\circ} \mathrm{C}$ for $30 \mathrm{~min}$, and finally at room temperature until being transferred to a submerged chamber where electrophysiological recordings were made at room temperature $\left(21^{\circ} \mathrm{C}-24^{\circ} \mathrm{C}\right.$ ) (within $6 \mathrm{~h}$ from cut).

Electrophysiological recordings, experimental design, and data analysis. The recording chamber was mounted on the stage of an upright microscope (Eclipse E600FN, Nikon Instruments), and slices were continuously perfused with standard ACSF (in mM as follows: $125 \mathrm{NaCl}, 2.5 \mathrm{KCl}$, $1 \mathrm{MgCl}_{2}, 2 \mathrm{CaCl}_{2}, 25 \mathrm{NaHCO}_{3}, 1.25 \mathrm{NaH}_{2} \mathrm{PO}_{4}, 25$ glucose) saturated with $95 \% \mathrm{O}_{2} / 5 \% \mathrm{CO}_{2}$ at a flow rate of $3 \mathrm{ml} / \mathrm{min}$ using a peristaltic pump (Miniplus 3, Gilson).

Connectivity between the thalamus and the cortex was assessed with a field-recording electrode (a patch pipette filled with standard ACSF) placed in L4 of the barrel cortex while electrically stimulating thalamic afferents (every $10 \mathrm{~s}$, stimulus duration $100 \mu \mathrm{s}$; stimulus amplitude 200$250 \mu \mathrm{A}$ ) with a concentric bipolar tungsten electrode (TM33CCINS, World Precision Instruments) placed in the ventrobasal nucleus (VB) close to the border with the nucleus reticularis thalami, near the fimbria. Field responses $>100 \mu \mathrm{V}$ amplitude were considered as acceptable evidence for a reliable connection.

Whole-cell patch-clamp recordings were made following standard techniques. Electrical signals were recorded through a Multiclamp 700B amplifier and digitized using an Axon Digidata 1550 interface and pClamp software (Molecular Devices). Pipette resistance was 3-5 m $\Omega$. Currents were sampled at $10 \mathrm{kHz}$ and filtered at $2 \mathrm{kHz}$.

Patch pipettes contained the following (in mM): $126 \mathrm{~K}$-gluconate (130 in recording from FS interneurons), $6 \mathrm{KCl}, 4 \mathrm{MgATP}, 0.3 \mathrm{NaGTP}, 10$ 
Na-phosphocreatine, 10 HEPES, 0.2 EGTA, and $0.2 \%$ biocytin (pH 7.25 with $\mathrm{KOH}$ ).

Voltage measurements were corrected for the experimentally determined junction potential of $12 \mathrm{mV}$. Access resistance was monitored continuously throughout the experiments; experiments where it changed $>20 \%$ (or had access resistance $>25 \mathrm{M} \Omega$, without compensation) were excluded from the data.

L4 RS and FS neurons (deeper than $45 \mu \mathrm{m}$ from the slice surface) were identified according to their morphology under infrared differential interference contrast optics (water-immersion objective $60 \times$ ), their spiking pattern in response to pulses of depolarizing current, their membrane time constant and input resistance, and the kinetics of their TC EPSC recorded at the reversal potential (Erev) of the IPSC (see below). In a subset of experiments, the identification was confirmed by postfixation inspection of the biocytin-labeled neurons. The firing pattern of the recorded neurons was determined immediately after rupturing the membrane by injecting $600 \mathrm{~ms}$ current pulses of incremental amplitude in the current-clamp mode. RS neurons were identified by their rapid adaptation of the instantaneous firing frequency in response to a square pulse of current (at 1.6-2 times the rheobase: from a peak frequency of $116 \pm 11 \mathrm{~Hz}$ [first two spikes] to a frequency of $23 \pm 2 \mathrm{~Hz}$ [averaged over $200 \mathrm{~ms}, 400-600 \mathrm{~ms}$ after the beginning of the pulse] in WT slices; $n=25$ cells), a relatively long membrane time constant (15.6 $\pm 0.9 \mathrm{~ms})$, a high input resistance in response to a $50 \mathrm{pA}$ negative current pulse (268 \pm 8 $\mathrm{M} \Omega), n=16$ ). FS interneurons were identified by their larger soma, higher firing rates, and a much less pronounced adaptation of the firing frequency: from a peak frequency of $167 \pm 12 \mathrm{~Hz}$ to a frequency of $110 \pm$ $9 \mathrm{~Hz}$ at $1.6-2$ times the rheobase in WT slices, $n=17$, a faster membrane time constant $(7.4 \pm 0.4 \mathrm{~ms})$, and a lower input resistance $(69 \pm 5 \mathrm{~m} \Omega)$ compared with RS neurons. Moreover the kinetics of the isolated EPSC elicited in FS interneurons by thalamic stimulation were much faster than those in RS neurons (half-width values: $2.3 \pm 0.2 \mathrm{~ms}, n=17$ vs $6.9 \pm 0.4 \mathrm{~ms}, n=25, p=9 \times 10^{-8}$, Mann-Whitney test; see Figs. 1, 2).

Synaptic responses evoked by thalamic stimulation were recorded at $-62 \mathrm{mV}$ and at Erev of the IPSC $(-85 \mathrm{mV})$ in voltage-clamped L4 RS neurons (as in Gabernet et al., 2005). The voltage of $-62 \mathrm{mV}$ is between Erev of excitatory and inhibitory postsynaptic currents and allows to accurately measure both the TC monosynaptic EPSC and disynaptic IPSC (dIPSC) at a voltage relatively close to the physiological resting potential (Gabernet et al., 2005). The dIPSC evoked by thalamic stimulation in RS neurons at $-62 \mathrm{mV}$ was isolated by scaling the EPSC recorded in isolation at Erev IPSC to the initial slope of the EPSC recorded at $-62 \mathrm{mV}$, and then subtracting this scaled EPSC to the synaptic current recorded at $-62 \mathrm{mV}$ (Gabernet et al., 2005) (see Fig. 1A). Thalamic stimulation: single pulses and trains of 5 pulses (100 $\mu$ s duration) at 10 $\mathrm{Hz}$ every $15 \mathrm{~s}$, or trains of 5 pulses at $40 \mathrm{~Hz}$ every $20 \mathrm{~s}$. The stimulus intensity was close to that eliciting the maximal synaptic response (range $120-250 \mu \mathrm{A}$ ) and, on average, was similar in WT and FHM1 slices (WT: $200 \pm 8 \mu \mathrm{A}, n=25$; FHM1 $=193 \pm 7 \mu \mathrm{A}, n=27$ ).

Synaptic responses evoked by thalamic stimulation were recorded in voltage-clamped FS interneurons at Erev of the IPSC. In a subset of experiments, the amplifier was then switched to current clamp (CC) to record in the same FS interneurons the voltage changes elicited by the thalamic stimulation. CC experiments were performed at the resting potential (Vrest) of the neurons without injecting any current (Vrest FS neurons: $\mathrm{WT}=-80 \pm 1 \mathrm{mV}, n=11$; FHM1 $=-81 \pm 1 \mathrm{mV}, n=14)$.

To ensure that the observed responses resulted from orthodromic stimulation of the TC axons rather than antidromic stimulation of corticothalamic axons, we routinely determined three electrophysiological parameters of the response: namely, latency, paired pulse ratio (PPR), and supernormality. We only considered experiments in which EPSCs recorded in L4 occurred at short latencies $(<3.5 \mathrm{~ms})$, showed paired pulses depression, and displayed no supernormality (i.e., decrease in latency of the second EPSC elicited $100 \mathrm{~ms}$ or less after the first) (Gabernet et al., 2005).

Statistics. Statistical analyses were performed with Statgraphics centurion XVII software (RRID:SCR_015248). After assessing for normal distribution (using the Shapiro-Wilk normality test), comparison between two groups was made using two-tailed unpaired or paired $t$ test for nor- mal distributed data and the Mann-Whitney or Wilcoxon tests for nonparametric data. Equal variances were assumed. ANOVA for repeated measures was used for comparison of two groups of multiple measurements on the same cells (e.g., responses to $10 \mathrm{~Hz}$ thalamic stimulation). The significance level was set to $p<0.05$. Data are given as mean \pm SEM. The number $n$ of observations (which are indicated in the text and figure legends) indicates the number of cells recorded from, whereas the number $N$ indicates the number of mice from which the recordings were obtained. The number of cells per group varied for different experiments, in most of which it was $>16$ (and $N>9$ ). No statistical methods were used to choose sample sizes that were estimated based on previous experience and are in line with those in the literature. No animals were excluded from the analysis. The traces in the figures are averages of traces from $n$ cells, which were obtained by averaging at least 20 sweeps in each cell.

\section{Results}

We recorded the synaptic currents evoked in L4 RS principal neurons of somatosensory barrel cortex by stimulation of TC afferents with an extracellular electrode placed in the VB of the thalamus in TC slices from P16-P19 WT and FHM1 knock-in mice carrying the R192Q mutation (FHM1 mice; Fig. 1A) (van den Maagdenberg et al., 2004). This FHM1 mutation in humans causes pure FHM (Ophoff et al., 1996). L4 RS neurons were identified according to their morphology, spiking pattern, and other electrophysiological properties as described in Materials and Methods. To identify the barrel connected with the VB stimulation site, the whole-cell patch-clamp recordings were preceded by extracellular recordings in L4 while electrically stimulating the VB.

Consistent with previous reports (Gabernet et al., 2005; Cruikshank et al., 2007), when RS neurons were voltage-clamped at -62 $\mathrm{mV}$, thalamic stimulation evoked a brief EPSC followed with a short delay ( $1.19 \pm 0.07 \mathrm{~ms}$ in WT slices, $n=25$ ) by an IPSC (Fig. $1 A$, top). The brief delay indicates that the IPSC is elicited in a feedforward, disynaptic manner, by thalamic excitation of L4 cortical inhibitory interneurons, which, according to previous work, are FS interneurons (Gabernet et al., 2005; Cruikshank et al., 2007). The disynaptic TC feedforward inhibition effectively curtails and suppresses TC excitation of RS cells, thus setting a very brief time window for temporal integration of thalamic inputs (Gabernet et al., 2005). Indeed, both the amplitude and duration of the EPSC evoked at $-62 \mathrm{mV}(69 \pm 9 \mathrm{pA}$ and $1.14 \pm$ $0.09 \mathrm{~ms}$ half-width in WT slices, $n=25$ ) were smaller than those of the EPSC evoked in L4 RS neurons voltage-clamped at Erev of the IPSC (Fig. $1 A$, middle; $144 \pm 14 \mathrm{pA}$ and $6.9 \pm 0.4 \mathrm{~ms}$ halfwidth, WT, $n=25, p=10^{-5}$, Wilcoxon test and $p=2 \times 10^{-8}$, $t$ test). The TC feedforward dIPSC at $-62 \mathrm{mV}$ (Fig. $1 A$, bottom, green) was isolated as in Gabernet et al. (2005) (compare Materials and Methods; Fig. 1A, legend).

The TC EPSC (recorded at Erev of IPSC) in L4 RS neurons was 1.8 times larger in FHM1 compared with WT mice (Fig. 1B, left), thus revealing a gain of function of excitatory neurotransmission at TC synapses on RS neurons (TC-RS synapses) similar to that previously found at different intracortical layer 2/3 (L2/3) excitatory synapses (Tottene et al., 2009; Marchionni, Pilati, Pietrobon, unpublished observations). Moreover, in FHM1 mice, the TC EPSC occurred with a slightly shorter delay from thalamic stimulation (FHM1: $2.47 \pm 0.06 \mathrm{~ms}, n=27$, vs WT: $2.72 \pm 0.07$ ms, $n=25 ; p=0.01, t$ test). The TC feedforward dIPSC in RS neurons was also $\sim 2$ times larger in the mutant mice (Fig. $1 B$, right). The increased TC disynaptic feedforward inhibition in FHM1 mice is expected if the excitatory synaptic transmission at TC synapses on L4 FS interneurons (TC-FS synapses) is also enhanced; and, as a consequence, recruitment of FS interneurons is increased. 
A
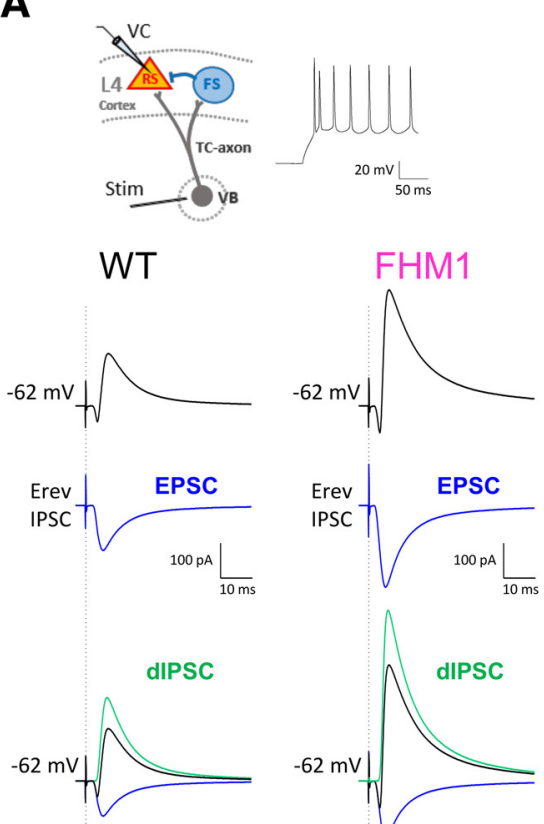

$\operatorname{sTIM} \uparrow$
B


Figure 1. The TC synaptic transmission is enhanced in FHM1 mice. $A$, Top, Schematic diagram of the experimental configuration in which synaptic currents evoked by thalamic stimulation were recorded in a voltage-clamped L4 RS neuron, and representative trace of the intrinsic firing of RS neurons. VC, Voltage clamp. Bottom, Average current responses elicited by single thalamic stimulations in L4 RS neurons voltage-clamped at $-62 \mathrm{mV}$ (top, black) and at the reversal potential (Erev) of the IPSC ( $-85 \mathrm{mV}$; middle, blue) in WT ( $n=25$, from N=23 mice) and FHM1 slices $(n=27 ; N=23)$. The feedforward dIPSC at $-62 \mathrm{mV}$ (bottom, green) was isolated by subtracting the scaled EPSC (bottom, blue; obtained by scaling to $-62 \mathrm{mV}$ the EPSC recorded in isolation at Erev of the IPSC) from the current recorded at $-62 \mathrm{mV}$ (bottom, black). $\boldsymbol{B}$, Left, Amplitudes and average value of the TC EPSC elicited in L4 RS neurons at Erev of IPSC by single thalamic stimulations in WT (average value: $144 \pm 14 \mathrm{pA}, n=25, N=23$; black) and FHM1 mice (255 $\pm 23 \mathrm{pA}, n=27, N=23$; magenta) and corresponding average traces. Right, Amplitudes and average values of the TC feedforward dIPSCs at $-62 \mathrm{mV}$ (isolated as described above) in WT ( $255 \pm 22 \mathrm{pA}, n=25, N=23$; black) and FHM1 mice (524 $\pm 49 \mathrm{pA}, n=27, N=23 ;$ magenta) and corresponding average traces. The TC EPSC and the TC dIPSC evoked by thalamic stimulation in L4 RS neurons are both $\sim 2$ times larger in FHM1 compared with WT mice: $p=2 \times 10^{-4}, t$ test and $p=6 \times 10^{-6}$, Mann-Whitney test, respectively. ${ }^{* * *} p<0.001$.

Indeed, recordings in L4 FS interneurons (voltage-clamped at Erev of IPSC) showed that the TC EPSC elicited by thalamic stimulation in these inhibitory neurons was 2 times larger in mutant compared with WT mice (Fig. 2A). Switching to CC (at resting potential) revealed that the average percentage of trials in which thalamic stimulation elicited a spike in the same FS interneurons was also near to 2 times larger in FHM1 compared with WT mice (Fig. 2B). Thus, the enhancement of TC excitatory transmission onto L4 FS interneurons results in a similarly increased recruitment of these interneurons by thalamic stimulation in FHM1 mice. This may account for the increased TC disynaptic feedforward inhibition on RS neurons. Therefore, these data are consistent with the hypothesis that action potential-evoked GABA release at L4 FS interneuron to RS neuron synapses is unaltered in FHM1 mice, in agreement with the unaltered synaptic transmission measured at L2/3 FS interneuron to pyramidal cell synapses (Tottene et al., 2009).

Consistent with previous reports (Gabernet et al., 2005; Cruikshank et al., 2007), the TC EPSC elicited (at Erev of IPSC) in WT FS interneurons was 6.3 times larger and had much faster kinetics than that elicited in WT RS neurons (half-width of average EPSC traces in Fig. $2 A$ and Fig. $1 B: 2.9 \mathrm{~ms}$ and $7.2 \mathrm{~ms}$, respectively). This has been shown to reflect both the expression of different AMPA receptors in FS and RS neurons and a larger number of thalamic inputs converging on FS compared with RS cells (Gabernet et al., 2005; Inoue and Imoto, 2006; Cruikshank et al., 2007; Hull et al., 2009).

Due to the similar gain of function of TC monosynaptic excitation and disynaptic feedforward inhibition of L4 RS neurons in
FHM1 mice, the TC feedforward inhibition over excitation ratio (I/E: ratio of isolated dIPSC and isolated monosynaptic EPSC scaled at $-62 \mathrm{mV}$ ) was similar in mutant and WT mice (Fig. 3). As a consequence, also the half-width duration (HW) of the EPSC recorded at $-62 \mathrm{mV}$ in RS neurons was similar in the two genotypes (Fig. 3). These findings support the conclusion that, considering single thalamic stimuli, the excitation-inhibition balance set by the TC FFI microcircuit in L4 RS neurons is not altered by the FHM1 mutation. Moreover, they suggest that also the brief time window for integration of TC synaptic inputs, which is mainly defined by the TC I/E ratio (Gabernet et al., 2005), is most likely unaltered in FHM1 mice (as indicated by the unaltered EPSC HW).

We next investigated whether the excitation-inhibition balance in the TC FFI microcircuit is altered in the FHM1 mice during repetitive thalamic stimulation. In slices from WT mice, during repetitive thalamic stimulation at $10 \mathrm{~Hz}$, the amplitudes of both the isolated EPSCs and feedforward dIPSCs elicited in RS neurons decreased with increasing pulse number, but the depression of the dIPSC was larger than that of the EPSC (Fig. 4A). As a consequence, the I/E ratio decreased during the train (from 2.7 at the first pulse to 0.15 at the fifth pulse) and the HW of the EPSC recorded at $-62 \mathrm{mV}$ in RS neurons increased (from 1.1 to $5.7 \mathrm{~ms}$, i.e., from $16 \%$ to $83 \%$ of the duration of the isolated EPSC recorded at Erev of IPSC) (Fig. 4B). This is in agreement with previous evidence that, in WT mice, the TC excitatory-inhibitory balance shifts toward excitation and the integration time window widens during repetitive thalamic stimulation (Gabernet et al., 2005). 
A

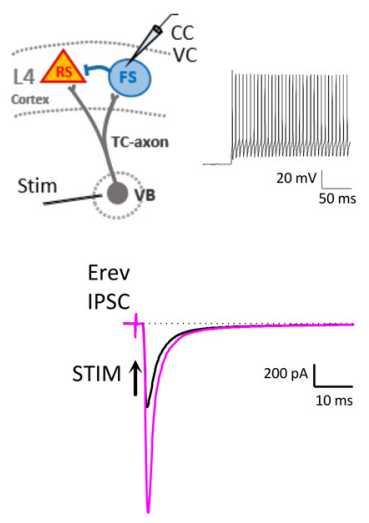

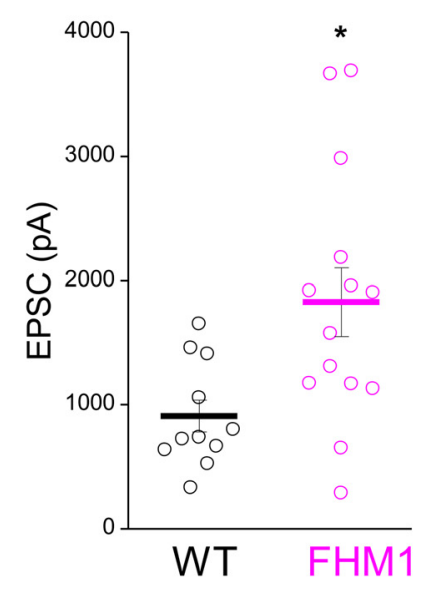

B



Figure 2. The recruitment of L4FS interneurons is enhanced in FHM1 mice. A, Left, Schematic diagram of the experimental configuration in which synaptic currents in voltage-clamp (VC) and voltage changes in CC evoked by thalamic stimulation were recorded in a L4 FS interneuron, and representative trace of the intrinsic firing of FS interneurons. The traces under the diagram are the average current responses elicited by single thalamic stimulations in L $4 \mathrm{FS}$ interneurons voltage-clamped at Erev of the IPSC in WT (black, $n=11, N=8$ ) and FHM1 mice (magenta, $n=14, N=$ 10). The fraction of thalamic stimulations eliciting firing in the same FS interneurons was then determined after switching to CC mode. Right, Amplitudes and average values of the TC EPSCs elicited in L4 FS interneurons at Erev of IPSC by single thalamic stimulations in WT ( $911 \pm 129 \mathrm{pA}, n=11$; black) and FHM1 mice (1830 $\pm 275 \mathrm{pA}, n=14$; magenta). The TC EPSC evoked by thalamic stimulation in L4FS interneurons is 2 times larger in FHM1 compared with WT mice $(p=0.011, t$ test). $\boldsymbol{B}$, Representative traces of the voltage changes measured in $C($ and the corresponding synaptic currents measured in VC in a WT (black) and an FHM1 (magenta) L4 FS interneuron. The average percentage of trials in which thalamic stimulation elicited a spike in FS interneurons was larger in FHM1 compared with WT mice $(75 \pm 11 \%$ in FHM1, $n=14$, vs $42 \pm 15 \%$ in WT, $n=11) .{ }^{*} p<0.05$.
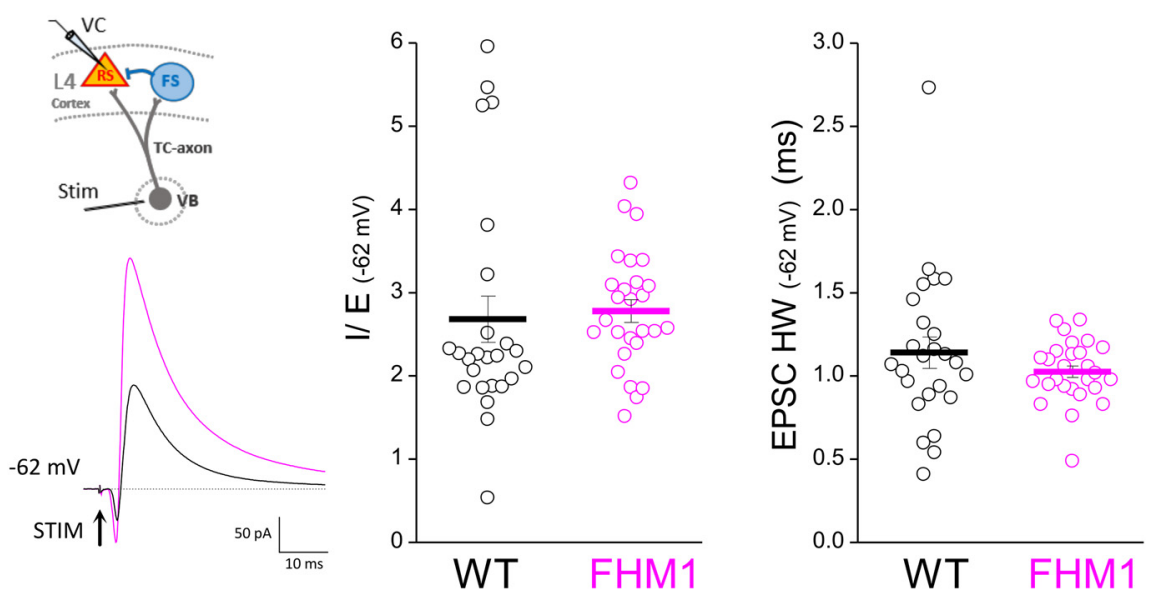

Figure 3. The TC feedforward inhibition over excitation ratio and the duration of TC excitation of L4 RS neurons are both unaltered in FHM1 mice. Left, Schematic diagram of experimental configuration and average current responses elicited in L4 RS neurons voltage-clamped at $-62 \mathrm{mV}$ by thalamic stimulation in WT $(n=25, N=23)$ and FHM1 mice $(n=27, N=23)$. Middle, Values of the TC feedforward I/E ratio elicited in L4 RS neurons by thalamic stimulation in WT $(2.7 \pm 0.3, n=25, N=23$; black) and FHM1 ( $2.8 \pm 0.1, n=27, N=23$; magenta) mice. The I/E ratio is obtained by dividing the dIPSC measured at $-62 \mathrm{mV}$ (isolated as in Fig. 1) by the isolated monosynaptic EPSC measured, as in Figure 1 and scaled at $-62 \mathrm{mV}$. The I/E ratio is not significantly different in FHM1 and WT mice ( $p=0.062$, Mann-Whitney test). Right, Values of the HW of the EPSC elicited in RS neurons voltage-clamped at $-62 \mathrm{mV}$ in WT ( $1.14 \pm 0.09 \mathrm{~ms}$ in WT, $n=25, N=23$; black) and FHM1 (1.03 $\pm 0.04 \mathrm{~ms}, n=27$, $N=23$; magenta) mice. The HW is not significantly different in WT and FHM1 mice ( $p=0.43$ Mann-Whitney test).

Short-term depression (STD) of the isolated EPSC at TC-RS synapses during repetitive thalamic stimulation was larger (and the PPR, lower) in FHM1 compared with WT mice (Fig. 5A). This is expected if an increased probability of glutamate release underlies the gain of function of TC excitatory transmission in FHM1 mice, as was previously shown for the gain of function of excitatory transmission at intracortical synapses (Tottene et al., 2009). The relative gain of function of the EPSC in the mutant mice decreased with increasing pulse number during the repetitive stimulation (by $\sim 35 \%$ at the fifth pulse). However, the EPSC remained significantly larger throughout the train in FHM1 compared with
WT mice (Fig. 5A). In striking contrast, STD of the feedforward dIPSC was unaltered in FHM1 mice (Fig. 5B). Therefore, the relative gain of function of the TC feedforward inhibition in the mutant mice remained nearly constant during the repetitive thalamic stimulation (Fig. 5B).

As a consequence of the differential effect of the FHM1 mutation on STD of TC excitation and TC disynaptic feedforward inhibition, the relative decrease of the I/E ratio in L4 RS cells during repetitive thalamic stimulation was smaller in FHM1 compared with WT mice (Fig. 6). During the train, the I/E ratio becomes increasingly larger in FHM1 compared with WT mice. Accordingly, the relative increase of the $\mathrm{HW}$ of the EPSC recorded at $-62 \mathrm{mV}$ in RS neurons during the train was lower in FHM1, and the HW becomes smaller in FHM1 compared with WT mice (Fig. 6). At the fifth pulse, the HW of the EPSC (at $-62 \mathrm{mV}$ ) was $63 \%$ of the HW of the isolated EPSC in FHM1 mice (vs $83 \%$ in WT mice). These findings are consistent with the conclusion that both the typical shift of the excitatory-inhibitory balance toward excitation and the typical widening of the integration time window during repetitive thalamic stimulation are smaller in FHM1 compared with WT mice. We have thus revealed an altered regulation of the cellular excitatory-inhibitory balance of TC-evoked responses in cortical L4 principal neurons during repetitive thalamic stimulation in FHM1. In contrast with what one might have expected, the dysregulation does not skew the balance toward excitation. This is further supported by the findings in Figure 7.

Repetitive thalamic stimulation in WT slices induced, in some trials, large barrages of EPSCs in L4 RS neurons (Fig. 7). The 



Figure 4. During repetitive thalamic stimulation, the TC feedforward inhibition over excitation ratio decreases and the duration of TC excitation of L4 RS neurons increases in WT mice. A, Left, Schematic diagram of experimental configuration and average current responses $(n=21, N=19)$ measured in WT L4 RS neurons voltage-clamped at $-62 \mathrm{mV}$ (top, black) and at Erev of the IPSC (middle, blue) during repetitive thalamic stimulation at $10 \mathrm{~Hz}$ (5 pulses). The feedforward dIPSC at $-62 \mathrm{mV}$ (bottom, green) was isolated as in Figure 1. Right, Average normalized TC EPSC (at Erev of the IPSC) and dIPSC (at $-62 \mathrm{mV}$ ) evoked in WT L4 RS neurons by repetitive $10 \mathrm{~Hz}$ thalamic stimulation as a function of stimulus number $(n=21, N=19)$. The depression of the dIPSC with increasing stimulus number is larger than that of the EPSC: EPSCPPR $=0.77 \pm 0.03$ and EPSC5/EPSC1 $=0.47 \pm 0.02 ; \mathrm{dIPSCPPR}=0.35 \pm 0.04$ and $\mathrm{dIPSC} / \mathrm{dlPSC}=0.03 \pm 0.01 ; p=2 \times$ $10^{-10}$ and $3 \times 10^{-14}$ (paired $t$ test) for PPR and PSC5/PSC1, respectively. $B$, Average values of the TCI/E ratio (obtained as in Fig. 3, $\bigcirc$ ) and of the HW of the EPSC $(O)$ elicited in L4 RS neurons (at $-62 \mathrm{mV}$ ) by repetitive thalamic stimulation as a function of stimulus number. The $\mathrm{I} / \mathrm{E}$ ratio decreases during the train (from $2.7 \pm 0.3$ at the first pulse to $1.3 \pm 0.2$ at the second pulse to $0.15 \pm$ 0.03 at the fifth pulse of the $10 \mathrm{~Hz}$ train). Hence, the HW of the EPSC recorded at $-62 \mathrm{mV}$ increases from $1.1 \pm 0.1 \mathrm{~ms}$ at the first pulse to $2.3 \pm 0.3 \mathrm{~ms}$ at the second pulse to $5.7 \pm 0.4 \mathrm{~ms}$ at the fifth pulse. ${ }^{* * *} p<0.001$.

fraction of trials in which these EPSC barrages were observed was 2.6 times larger after $40 \mathrm{~Hz}$ compared with $10 \mathrm{~Hz}$ thalamic stimulation (Fig. 7). Previous work has shown that these frequencydependent EPSC barrages are produced by recurrent network activity recruited via intracortical synapses as a consequence of firing of a small number of L4 RS neurons after temporal summation of TC EPSPs that overcomes TC feedforward inhibition (Beierlein et al., 2002). In agreement with the relatively smaller shift of the excitatory-inhibitory balance toward excitation during repetitive stimulation in FHM1 compared with WT mice, recurrent cortical network activity induced by repetitive thalamic stimulation was observed less frequently in the FHM1 mutants (Fig. 7).

To investigate why, despite the gain of function of TC excitation of L4 FS interneurons (Fig. 2), the STD of the TC feedforward dIPSC on RS neurons was unaltered in FHM1 mice (Fig. $5 B$ ), we recorded the TC EPSCs elicited in L4 FS interneurons by repetitive thalamic stimulation at $10 \mathrm{~Hz}$. In striking contrast with the increased STD of excitatory transmission at FHM1 TC-RS synapses (Fig. $5 A$ ) and FHM1 L2/3 pyramidal cell-FS interneuron synapses (Tottene et al., 2009), the STD of excitatory transmission at TC-FS interneuron synapses was similar in WT and FHM1 mice (Fig. 8). As a consequence, the relative gain of function of TC excitation of L4 FS interneurons in FHM1 mice remained nearly constant during the repetitive thalamic stimulation (Fig. 8). The similar STD of excitatory transmission at TC-FS interneuron synapses in WT and FHM1 mice may account for the similar STD of the TC disynaptic feedforward inhibition in the two genotypes (Fig. 5B).

\section{Discussion}

In this study, we show that TC synaptic transmission is enhanced in FHM1 compared with WT mice. The monosynaptic EPSCs evoked by single pulse thalamic stimulation on L4 RS neurons and FS interneurons are similarly enhanced. The consequent in- creased recruitment of FS interneurons results in a similar enhancement of disynaptic FFI inputs on L4 principal neurons. As a consequence, in response to single thalamic stimulations, neither the excitatory-inhibitory balance nor the integration time window set by the TC FFI microcircuit in RS neurons is significantly altered in the FHM1 mutants. However, during repetitive thalamic stimulation, the typical shift of the excitatory-inhibitory balance toward excitation and the typical widening of the integration time window (Gabernet et al., 2005) are both smaller in FHM1 compared with WT mice. Although TC synaptic excitation of L4 neurons remains enhanced, during repetitive thalamic activity, the excitatory-inhibitory balance in L4 RS neurons is relatively skewed toward inhibition in FHM1 compared with WT mice. We have thus revealed a dysregulation of the excitatoryinhibitory balance set by the TC FFI microcircuit in FHM1. This is due to an unexpected differential effect of the FHM1 mutation on short-term synaptic plasticity at TC-RS and TC-FS excitatory synapses. STD is enhanced at TC-RS synapses, as expected for an increased probability of glutamate release due to gain of function of presynaptic $\mathrm{Ca}_{\mathrm{v}} 2.1$ channels (Tottene et al., 2009) but is unaltered at TC-FS synapses in FHM1 mice, despite the gain of function of neurotransmitter release.

Since a single TC axon can impinge on both RS and FS cells (Gabernet et al., 2005; Inoue and Imoto, 2006), these findings indicate postsynaptic target cell-dependent plasticity at TC synapses (Larsen and Sjöström, 2015). There is evidence that STD at TC-FS synapses involves mainly presynaptic mechanisms (Bagnall et al., 2011). However, the unaltered STD at TC-FS synapses in FHM1 mice, despite the larger probability of release (Tottene et al., 2009), suggests the presence of a target-cell specific STD mechanism that is independent of the initial probability of release. This implies that, at TC-FS, in contrast with TC-RS, synapse vesicle depletion is not the main STD mechanism. Different hypothetical presynaptic STD mechanisms upstream of exocyto- 
A


B
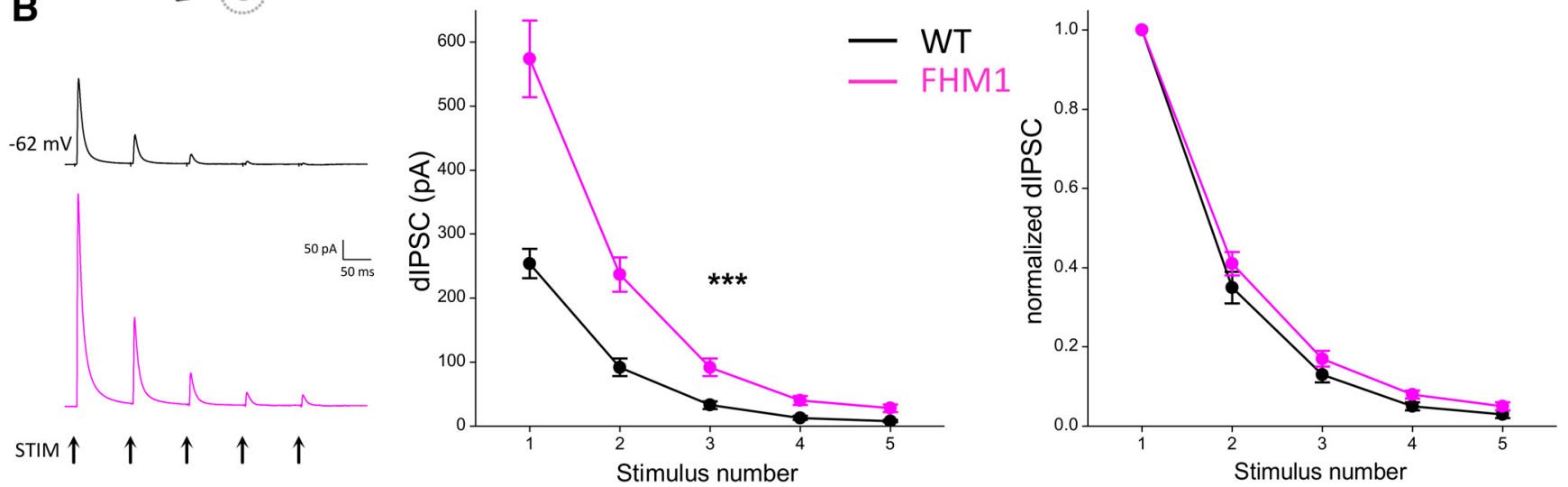

Figure 5. During repetitive thalamic stimulation, STD of TC excitation of L4 RS neurons is larger in FHM1 compared with WT mice, whereas STD of TC feedforward inhibition is unaltered in FHM1 mice. A, Left, Schematic diagram of experimental configuration and average current responses measured in L4 RS neurons voltage-clamped at Erev of the IPSC in WT ( $n=21, N=19$ ) and FHM1 $(n=20, N=19)$ mice during repetitive thalamic stimulation (10 Hz). Middle, Average amplitudes of the isolated TC EPSC in RS neurons as a function of pulse number in WT (black, $n=21, N=$ 19) and FHM1 (magenta, $n=20, N=19$ ) mice. Right, The average values of the EPSC amplitudes normalized to the EPSC elicited by the first pulse in each cell. The depression of the isolated EPSC during repetitive thalamic stimulation is larger in FHM1 compared with WT mice: $\mathrm{EPSCPPR}=0.66 \pm 0.03$ in FHM1 versus $0.77 \pm 0.03$ in WT, $p=0.017, t$ test; $\mathrm{EPSC} / \mathrm{EPSC} 1=0.38 \pm 0.03$ versus $0.47 \pm 0.02, p=0.020, t$ test. However, the EPSC remains significantly larger throughout the train in FHM1 compared with WT mice (middle: $p=0.0018$, repeated-measures ANOVA). $\boldsymbol{B}$, Left, Average traces of the feedforward dIPSC in RS neurons at $-62 \mathrm{mV}$ (isolated as in Fig. 1) during repetitive thalamic stimulation in WT $(n=21)$ and FHM1 $(n=20)$ mice. Middle, Average amplitudes of the isolated TC feedforward dIPSC in RS neurons as a function of pulse number in WT (black, $n=21$ ) and FHM1 (magenta, $n=20)$ mice $(p<0.0001$, repeated-measures ANOVA). Right, Average normalized dIPSC amplitudes in RS neurons as a function of pulse number in WT and FHM1 mice. The depression of the TC dIPSC during repetitive thalamic stimulation is similar in FHM1 and WT mice: $\mathrm{dIPSCPPR}=0.41 \pm 0.03$, in FHM1 versus $0.35 \pm 0.04$ in WT; $p=0.22, t$ test; dIPSC5/dIPSC1 $=0.05 \pm 0.01$ in FHM1 versus $0.03 \pm 0.01$ in WT, $p=0.17, t$ test. ${ }^{*} p<0.05 .{ }^{* *} p<0.01 .{ }^{* * *} p<$ 0.001 .

sis and presynaptic $\mathrm{Ca}^{2+}$ influx may be consistent with unaltered STD in FHM1 mice. They include activity-dependent changes in amplitude and/or duration of the presynaptic spike resulting in reduced $\mathrm{Ca}^{2+}$ influx during the train (Kawaguchi and Sakaba, 2015) and activity-dependent inactivation of the release machinery or reduced affinity of the presynaptic $\mathrm{Ca}^{2+}$ sensor during the train (Kraushaar and Jonas, 2000; Waldeck et al., 2000). An increased open probability of mutant $\mathrm{Ca}_{\mathrm{v}} 2.1$ channels (Pietrobon, 2013) is expected to barely affect these STD mechanisms; and, if any, the effect would be a reduction of STD. The alternative hypothesis that, at TC-FS synapses, there are specific activitydependent mechanisms of facilitation that are enhanced in FHM1 and compensate the enhanced STD seems unlikely and in contrast with the larger STD at TC-FS compared with TC-RS synapses (Beierlein et al., 2003; Gabernet et al., 2005) (Figs. 5, 8).

The finding of increased TC synaptic transmission in the somatosensory cortex of FHM1 mice strongly suggests that transmission of sensory signals, including nociceptive trigeminovascular signals, from thalamic relay nuclei to cortex is enhanced by FHM1 mutations. This would increase the gain of the trigeminovascular pain pathway in FHM1 and thus facilitate migraine pain. It might contribute to the behavioral changes suggestive of unilateral head pain that were reported in FHM1 mice when subjected to novelty or restrain stress (Chanda et al., 2013). If our findings also hold for TC transmission from higher-order thalamic nuclei, such as dura-sensitive Po/LP, then increased TC transmission from these nuclei might contribute to allodynia and photophobia during the migraine attack (Burstein et al., 2010; Noseda et al., 2010). Moreover, since Po/LP neurons project broadly to several cortical areas, including visual, auditory, and parietal association areas (Noseda et al., 2011), and participate in trans-thalamic circuits mediating corticocortical communication (Sherman, 2016), increased TC transmission from these nuclei might contribute to the general enhancement of sensory gain that seems to characterize migraine (Brennan and Pietrobon, 2018). Indeed, migraineurs show amplification of percepts from multiple senses 

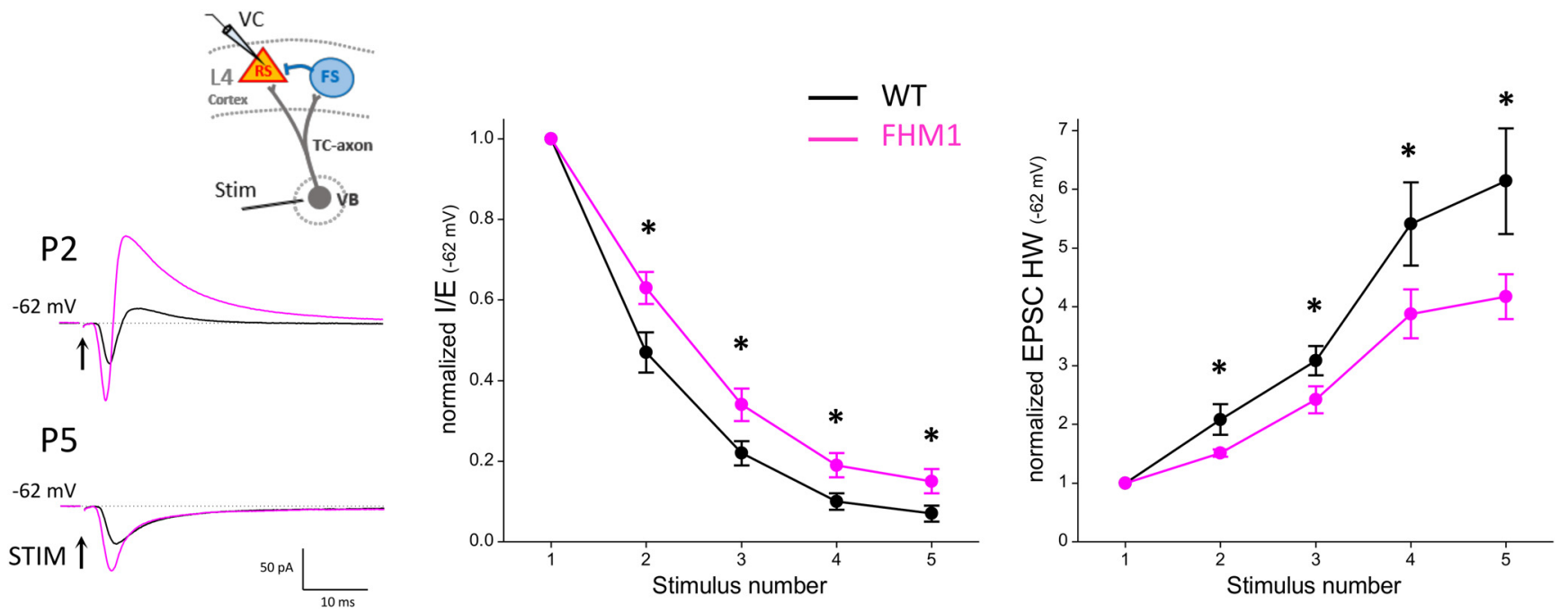

Figure 6. During repetitive thalamic stimulation, the relative decrease of the TC feedforward inhibition over excitation ratio and the relative increase of the duration of TC excitation of L4 RS neurons are both smaller in FHM1 compared with WT mice. Left, Schematic diagram of experimental configuration and average current responses elicited in L4 RS neurons (voltage-clamped at - 62 $\mathrm{mV})$ by the second and fifth pulse of repetitive thalamic stimulation at $10 \mathrm{~Hz}$ in WT $(n=21, N=19)$ and FHM1 $(n=20, N=19)$ mice. Middle, Average normalized values of the TC feedforward I/E ratio elicited in L4 RS neurons by repetitive thalamic stimulation as a function of stimulus number in WT ( $n=21, N=19$; black) and FHM1 ( $n=20, N=19 ;$ magenta) mice. During the train, the normalized $\mathrm{l} / \mathrm{E}$ ratio decreases less and becomes increasingly larger in FHM1 compared with WT mice: $0.63 \pm 0.04$ versus $0.47 \pm 0.05$ at the second pulse $(p=0.016, t$ test); $0.15 \pm 0.03$ versus $0.07 \pm 0.02$ at the fifth pulse ( $p=0.018, t$ test). Right, Average normalized values of the HW of the EPSC elicited in RS neurons (at $-62 \mathrm{mV}$ ) by repetitive thalamic stimulation as a function of stimulus number in WT ( $n=21$; black) and FHM1 ( $n=20$; magenta) mice. During the train, the normalized HW increases less and is smaller in FHM1 compared with WT mice: $1.51 \pm 0.06$ versus $2.1 \pm 0.3$ at the second pulse $\left(p=0.015\right.$, Mann-Whitney test); $4.2 \pm 0.4$ versus $6.1 \pm 0.9$ at the fifth pulse $\left(p=0.046\right.$, Mann-Whitney test). ${ }^{*} p<0.05$.


Figure 7. Recurrent cortical network activity induced by repetitive thalamic stimulation is less frequent in FHM1 compared with WT mice. Left, Representative traces of the current elicited in a WT and a FHM1 L4 RS neuron (voltage-clamped at Erev of IPSC) by a $10 \mathrm{~Hz}$ thalamic stimulation (5 pulses). The thalamic stimulation induces in some trials network activity visible as large barrages of EPSCS. Right, Percentage of trials in which 10 or $40 \mathrm{~Hz}$ thalamic stimulation induced recurrent network activity in WT (10 Hz: $n=63, N=37 ; 40 \mathrm{~Hz} ; n=20, N=7)$ and FHM1 mice $(10 \mathrm{~Hz}, n=$ $58, \mathrm{~N}=34 ; 40 \mathrm{~Hz} ; n=18, N=6$ ). The average percentage trials with network activity in WT slices increased with stimulation frequency from $28 \pm 4 \%$ of trials after $5 \mathrm{pulses}$ at $10 \mathrm{~Hz}$ to $73 \pm 8 \%$ of trials after 5 pulses at $40 \mathrm{~Hz}$ ( $p=1 \times 10^{-5}$, Mann-Whitney test). At both frequencies, the average percentage of trials with network activity is smaller in FHM1 than WT mice (12 $\pm 3 \%$ vs $28 \pm$ $4 \%$ at $10 \mathrm{~Hz}$ and $26 \pm 9 \%$ vs $73 \pm 8 \%$ at $40 \mathrm{~Hz} ; p=4 \times 10^{-4}$, Mann-Whitney test at both 10 and $40 \mathrm{~Hz}$ ). ${ }^{* * *} p<0.001$.

during the attack and interictal hypersensitivity to sensory stimuli and heightened responses to noxious and non-noxious sensory stimulation (de Tommaso et al., 2014; Schwedt et al., 2015; Demarquay and Mauguière, 2016; Schulte and May, 2016; Lisicki et al., 2018).

The dysregulation of the excitatory-inhibitory balance set by the TC FFI microcircuit in L4 principal neurons suggests that the temporal precision and the spatial focusing of cortical sensory responses might also be enhanced in FHM1. However, any pre- diction about possible alterations in these and other features of sensory processing modulated by the TC FFI microcircuit (see Introduction and references therein) is made difficult by the fact that they may also depend on intracortical recurrent excitation and inhibition and, in general, on the excitatory-inhibitory balance in the intracortical core microcircuits mediating feedback and feedforward inhibition and disinhibition (Isaacson and Scanziani, 2011; Tremblay et al., 2016). These microcircuits are likely altered by the FHM1 mutations, but in a presently un- 

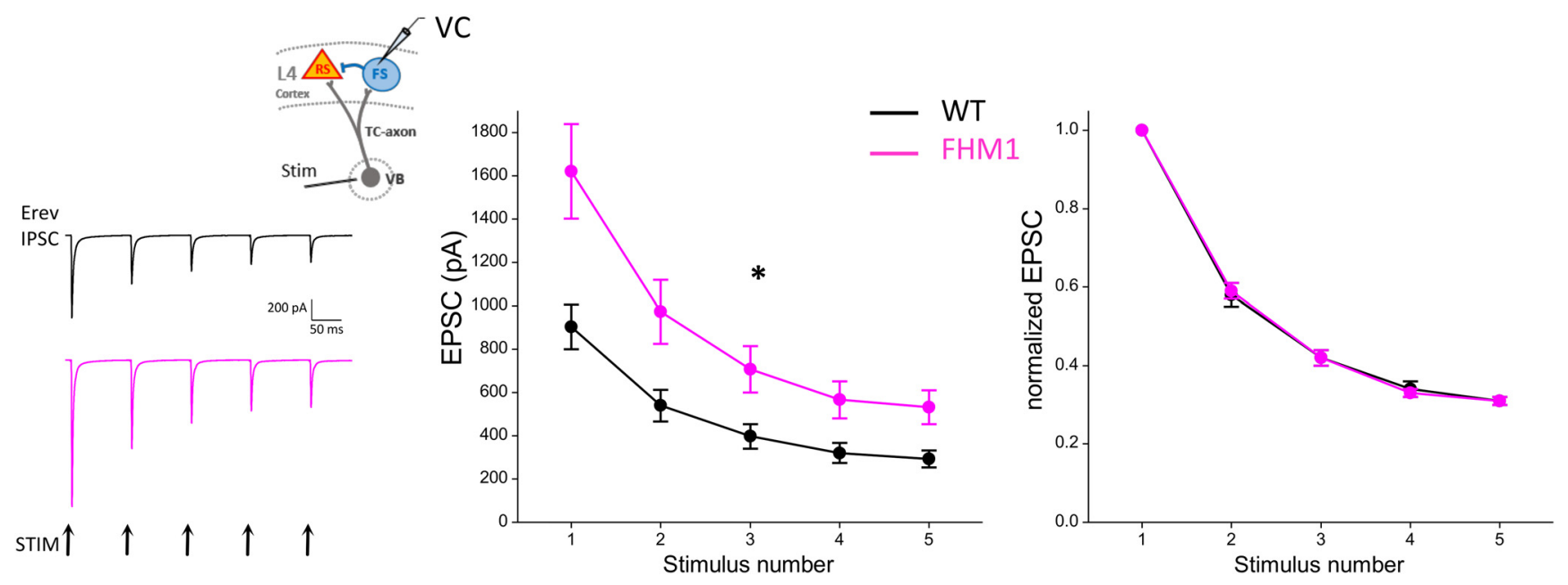

Figure 8. During repetitive thalamic stimulation, STD of TC excitation of L4 FS interneurons is unaltered in FHM1 mice. $\boldsymbol{A}$, Left, Schematic diagram of experimental configuration and average current responses measured in L4 FS interneurons voltage-clamped at Erev of the IPSC in WT ( $n=17, N=13)$ and FHM1 $(n=19, N=13)$ mice during repetitive thalamic stimulation (10 Hz). Middle, Average amplitudes of the isolated TC EPSC in FS interneurons as a function of pulse number in WT (black, $n=17, N=13$ ) and FHM1 (magenta, $n=19, N=13$ ) mice. The EPSC is significantly larger throughout the train in FHM1 compared with WT mice ( $p=0.012$, repeated-measures ANOVA). Right, Corresponding average normalized values of the EPSC amplitudes as a function of pulse number. The depression of the isolated EPSC during repetitive thalamic stimulation is unaltered in FHM1 mice (EPSC PPR $=0.59 \pm 0.02$ in FHM1 vs $0.58 \pm 0.03$ in WT; EPSC5/EPSC $1=0.31 \pm 0.01$ vs $0.31 \pm 0.01$ ). In WT mice, STD is larger at TC-FS compared with TC-RS synapses (compare PPR $=0.58 \pm 0.03$ vs $0.77 \pm 0.03, p=3 \times 10^{-5}, t$ test and EPSC5/1 $=$ $0.31 \pm 0.01$ vs $0.47 \pm 0.02, p=2 \times 10^{-6} t$ test) (Beierlein et al., 2003; Gabernet et al., 2005). ${ }^{*} p<0.05$.

known manner. Moreover, although the main properties of the TC FFI microcircuit uncovered in TC slices have been observed also in vivo in anesthetized WT animals (Chung et al., 2002; Gabernet et al., 2005; Higley and Contreras, 2006; Heiss et al., 2008), there are some differences: e.g., the release probability at individual synapses is generally lower (Borst, 2010) and, on the other hand, the number of TC fibers is much larger in vivo than in slices (resulting in an enhanced I/E ratio in L4 RS neurons due to the larger convergence of TC fibers on FS than RS neurons) (Bruno and Simons, 2002; Swadlow and Gusev, 2002; Inoue and Imoto, 2006; Cruikshank et al., 2007; Favero and Castro-Alamancos, 2013).

In vivo, the TC FFI microcircuit function is strongly modulated by the animal behavioral state. This is due to neuromodulation, which can affect differently TC feedforward inhibition and excitation of RS neurons: for instance, compare the effect of noradrenaline in Favero et al. (2012) and the very low threshold to sensory stimulation of L4 FS interneurons in awake animals in Simons (1978) and Swadlow (2003). It is also due to the fact that depressing synapses, such as the TC-RS and TC-FS synapses, are likely always in some state of depression, which correlates with ongoing thalamic firing rate (larger in awake alert-whisking than quiet animals and in awake than sleeping-anesthetized animals) (Castro-Alamancos and Oldford, 2002; Castro-Alamancos, 2004; Bruno and Sakmann, 2006; Poulet et al., 2012). We can then predict that the alterations of the TC FFI microcircuit in FHM1 are behavioral state-dependent. This feature might contribute to explain the episodic nature of the disease and why the same trigger may sometimes initiate a migraine attack and sometimes not. Future investigations of sensory processing in awake FHM1 mice in different behavioral states combined with investigations of the effect of the FHM1 mutations on the excitatory-inhibitory balance in the core intracortical microcircuits will be essential to understand how and by which mechanisms the FHM1 mutation affects sensory processing in behaving animals.

Perhaps counterintuitively, given the enhanced TC excitatory transmission, the dysregulation of the excitatory inhibitory balance in the TC FFI microcircuit in FHM1 mice does not skew the balance toward excitation and does not lead to cortical overexcitation. On the contrary, cortical recurrent excitation induced by repetitive thalamic firing is reduced in FHM1 mice. Interestingly, in contrast with our findings in the FHM1 mouse model, a skewing toward excitation of the excitatory-inhibitory balance of TCevoked responses in L4 RS neurons has been reported in some animal models of epilepsy. This dysregulation has been proposed to contribute to the unconstrained cortical recurrent excitation and the seizures observed in these animals (Sun et al., 2005; Sasaki et al., 2006; Paz and Huguenard, 2015). These include the tottering mice, which carry a loss-of-function mutation in the $\mathrm{Ca}_{\mathrm{V}} 2.1$ channel (Pietrobon, 2005; Sasaki et al., 2006) and are resistant to induction of experimental CSD (Ayata et al., 2000) (i.e., show the opposite $\mathrm{Ca}_{\mathrm{V}} 2.1$ and CSD phenotype than the FHM1 mice) (van den Maagdenberg et al., 2004; Tottene et al., 2009). Thus, a dysregulation of the excitatory-inhibitory balance in the TC FFI microcircuit does not seem to affect in an obvious manner CSD susceptibility. However, CSD susceptibility is clearly linked to $\mathrm{Ca}_{\mathrm{V}} 2.1$ channel function in intracortical neurons and to enhanced intracortical glutamatergic neurotransmission (Tottene et al., 2009, 2011; Capuani et al., 2016). The specific intracortical microcircuits involving excitatory and inhibitory neurons, whose dysfunctional regulation may underlie CSD susceptibility in FHM, remain unknown.

Some of the alterations in sensory processing revealed in migraineurs (e.g., in contrast gain of steady-state visual evoked potentials and in perceptual surround suppression) were interpreted as reflecting an excitatory-inhibitory imbalance toward inhibition in visual pathways, due to increased recruitment of inhibitory interneurons as a consequence of enhanced excitatory transmission (Battista et al., 2011; Nguyen et al., 2016). These interpretations are consistent with the dysregulation of the TC excitatory-inhibitory balance uncovered in FHM1 mice, with the caveat that the neural basis of perception and of the complex signals measured in clinical neurophysiological studies are poorly understood; therefore, it is very difficult to relate the response alterations in migraineurs to specific neuronal synaptic and circuit mechanisms. Interestingly, opposite alterations in contrast 
gain and surround suppression, consistent with reduced inhibition, were reported in epileptic and schizophrenic patients (Dakin et al., 2005; Tsai et al., 2011). Thus, some alterations in sensory processing in patients and the alterations in excitatory-inhibitory balance in the TC FFI microcircuit (and CSD susceptibility) in animal models point to different circuit mechanisms of dysregulation of the excitatory-inhibitory balance in migraine and epilepsy.

\section{References}

Agmon A, Connors BW (1991) Thalamocortical responses of mouse somatosensory (barrel) cortex in vitro. Neuroscience 41:365-379.

Ayata C, Shimizu-Sasamata M, Lo EH, Noebels JL, Moskowitz MA (2000) Impaired neurotransmitter release and elevated threshold for cortical spreading depression in mice with mutations in the $\mathrm{a}_{1 \mathrm{~A}}$ subunit of $\mathrm{P} / \mathrm{Q}$ type calcium channels. Neuroscience 95:639-645.

Bagnall MW, Hull C, Bushong EA, Ellisman MH, Scanziani M (2011) Multiple clusters of release sites formed by individual thalamic afferents onto cortical interneurons ensure reliable transmission. Neuron 71:180-194.

Battista J, Badcock DR, McKendrick AM (2011) Migraine increases centresurround suppression for drifting visual stimuli. PLoS One 6:e18211.

Beierlein M, Fall CP, Rinzel J, Yuste R (2002) Thalamocortical bursts trigger recurrent activity in neocortical networks: layer 4 as a frequency-dependent gate. J Neurosci 22:9885-9894.

Beierlein M, Gibson JR, Connors BW (2003) Two dynamically distinct inhibitory networks in layer 4 of the neocortex. J Neurophysiol 90:29873000.

Borst JG (2010) The low synaptic release probability in vivo. Trends Neurosci 33:259-266.

Brennan KC, Pietrobon D (2018) A systems neuroscience approach to migraine. Neuron 97:1004-1021.

Bruno RM (2011) Synchrony in sensation. Curr Opin Neurobiol 21:701708.

Bruno RM, Sakmann B (2006) Cortex is driven by weak but synchronously active thalamocortical synapses. Science 312:1622-1627.

Bruno RM, Simons DJ (2002) Feedforward mechanisms of excitatory and inhibitory cortical receptive fields. J Neurosci 22:10966-10975.

Burstein R, Jakubowski M, Garcia-Nicas E, Kainz V, Bajwa Z, Hargreaves R, Becerra L, Borsook D (2010) Thalamic sensitization transforms localized pain into widespread allodynia. Ann Neurol 68:81-91.

Burstein R, Noseda R, Borsook D (2015) Migraine: multiple processes, complex pathophysiology. J Neurosci 35:6619-6629.

Capuani C, Melone M, Tottene A, Bragina L, Crivellaro G, Santello M, Casari G, Conti F, Pietrobon D (2016) Defective glutamate and $\mathrm{K}^{+}$clearance by cortical astrocytes in familial hemiplegic migraine type 2. EMBO Mol Med 8:967-986.

Castro-Alamancos MA (2004) Dynamics of sensory thalamocortical synaptic networks during information processing states. Prog Neurobiol 74: 213-247.

Castro-Alamancos MA, Oldford E (2002) Cortical sensory suppression during arousal is due to the activity-dependent depression of thalamocortical synapses. J Physiol 541:319-331.

Chanda ML, Tuttle AH, Baran I, Atlin C, Guindi D, Hathaway G, Israelian N, Levenstadt J, Low D, Macrae L, O'Shea L, Silver A, Zendegui E, Mariette Lenselink A, Spijker S, Ferrari MD, van den Maagdenberg AM, Mogil JS (2013) Behavioral evidence for photophobia and stress-related ipsilateral head pain in transgenic Cacnala mutant mice. Pain 154:1254-1262.

Chung S, Li X, Nelson SB (2002) Short-term depression at thalamocortical synapses contributes to rapid adaptation of cortical sensory responses in vivo. Neuron 34:437-446.

Cruikshank SJ, Lewis TJ, Connors BW (2007) Synaptic basis for intense thalamocortical activation of feedforward inhibitory cells in neocortex. Nat Neurosci 10:462-468.

Dakin S, Carlin P, Hemsley D (2005) Weak suppression of visual context in chronic schizophrenia. Curr Biol 15:R822-R824.

Demarquay G, Mauguière F (2016) Central nervous system underpinnings of sensory hypersensitivity in migraine: insights from neuroimaging and electrophysiological studies. Headache 56:1418-1438.

de Tommaso M, Ambrosini A, Brighina F, Coppola G, Perrotta A, Pierelli F, Sandrini G, Valeriani M, Marinazzo D, Stramaglia S, Schoenen J (2014)
Altered processing of sensory stimuli in patients with migraine. Nat Rev Neurol 10:144-155.

Dugué GP, Dumoulin A, Triller A, Dieudonné S (2005) Target-dependent use of co-released inhibitory transmitters at central synapses. J Neurosci 25:6490-6498.

Favero M, Castro-Alamancos MA (2013) Synaptic cooperativity regulates persistent network activity in neocortex. J Neurosci 33:3151-3163.

Favero M, Varghese G, Castro-Alamancos MA (2012) The state of somatosensory cortex during neuromodulation. J Neurophysiol 108:1010-1024.

Filiz A, Tepe N, Eftekhari S, Boran HE, Dilekoz E, Edvinsson L, Bolay H (2019) CGRP receptor antagonist MK-8825 attenuates cortical spreading depression induced pain behavior. Cephalalgia 39:354-365.

Gabernet L, Jadhav SP, Feldman DE, Carandini M, Scanziani M (2005) Somatosensory integration controlled by dynamic thalamocortical feedforward inhibition. Neuron 48:315-327.

Goadsby PJ, Holland PR, Martins-Oliveira M, Hoffmann J, Schankin C, Akerman S (2017) Pathophysiology of migraine: a disorder of sensory processing. Physiol Rev 97:553-622.

Heiss JE, Katz Y, Ganmor E, Lampl I (2008) Shift in the balance between excitation and inhibition during sensory adaptation of S1 neurons. J Neurosci 28:13320-13330.

Higley MJ, Contreras D (2006) Balanced excitation and inhibition determine spike timing during frequency adaptation. J Neurosci 26:448-457.

Hull C, Isaacson JS, Scanziani M (2009) Postsynaptic mechanisms govern the differential excitation of cortical neurons by thalamic inputs. J Neurosci 29:9127-9136.

Inoue T, Imoto K (2006) Feedforward inhibitory connections from multiple thalamic cells to multiple regular-spiking cells in layer 4 of the somatosensory cortex. J Neurophysiol 96:1746-1754.

Isaacson JS, Scanziani M (2011) How inhibition shapes cortical activity. Neuron 72:231-243.

Kawaguchi SY, Sakaba T (2015) Control of inhibitory synaptic outputs by low excitability of axon terminals revealed by direct recording. Neuron 85:1273-1288.

Kraushaar U, Jonas P (2000) Efficacy and stability of quantal GABA release at a hippocampal interneuron-principal neuron synapse. J Neurosci 20: 5594-5607.

Larsen RS, Sjöström PJ (2015) Synapse-type-specific plasticity in local circuits. Curr Opin Neurobiol 35:127-135.

Leo L, Gherardini L, Barone V, De Fusco M, Pietrobon D, Pizzorusso T, Casari G (2011) Increased susceptibility to cortical spreading depression in the mouse model of familial hemiplegic migraine type 2. PLoS Genet 7:e1002129.

Lisicki M, D’Ostilio K, Coppola G, Maertens de Noordhout A, Parisi V, Schoenen J, Magis D (2018) Brain correlates of single trial visual evoked potentials in migraine: more than meets the eye. Front Neurol 9:393.

Moore CI (2004) Frequency-dependent processing in the vibrissa sensory system. J Neurophysiol 91:2390-2399.

Nguyen BN, McKendrick AM, Vingrys AJ (2016) Abnormal inhibitionexcitation imbalance in migraine. Cephalalgia 36:5-14.

Noseda R, Kainz V, Jakubowski M, Gooley JJ, Saper CB, Digre K, Burstein R (2010) A neural mechanism for exacerbation of headache by light. Nat Neurosci 13:239-245.

Noseda R, Jakubowski M, Kainz V, Borsook D, Burstein R (2011) Cortical projections of functionally identified thalamic trigeminovascular neurons: implications for migraine headache and its associated symptoms. J Neurosci 31:14204-14217.

Ophoff RA, Terwindt GM, Vergouwe MN, van EijK R, Oefner PJ, Hoffman SM, Lamerdin JE, Mohrenweiser HW, Bulman DE, Ferrari M, Haan J, Lindhout D, van Ommen GJ, Hofker MH, Ferrari MD, Frants RR (1996) Familial hemiplegic migrain and ataxia type- 2 are caused by mutations in the $\mathrm{Ca}^{2+}$ channel gene CACNL1A4. Cell 87:543-552.

Paz JT, Huguenard JR (2015) Microcircuits and their interactions in epilepsy: is the focus out of focus? Nat Neurosci 18:351-359.

Pietrobon D (2005) Function and dysfunction of synaptic calcium channels: insights from mouse models. Curr Opin Neurobiol 15:257-265.

Pietrobon D (2013) Calcium channels and migraine. Biochim Biophys Acta 1828:1655-1665.

Pietrobon D (2018) Ion channels in migraine disorders. Curr Opin Physiol 2:98-108.

Pietrobon D, Brennan KC (2019) Genetic mouse models of migraine. J Headache Pain 20:79. 
Pietrobon D, Moskowitz MA (2013) Pathophysiology of migraine. Annu Rev Physiol 75:365-391.

Pietrobon D, Moskowitz MA (2014) Chaos and commotion in the wake of cortical spreading depression and spreading depolarizations. Nat Rev Neurosci 15:379-393.

Poulet JF, Fernandez LM, Crochet S, Petersen CC (2012) Thalamic control of cortical states. Nat Neurosci 15:370-372.

Sasaki S, Huda K, Inoue T, Miyata M, Imoto K (2006) Impaired feedforward inhibition of the thalamocortical projection in epileptic $\mathrm{Ca}^{2+}$ channel mutant mice, tottering. J Neurosci 26:3056-3065.

Schulte LH, May A (2016) The migraine generator revisited: continuous scanning of the migraine cycle over 30 days and three spontaneous attacks. Brain 139:1987-1993.

Schwedt TJ, Chiang CC, Chong CD, Dodick DW (2015) Functional MRI of migraine. Lancet Neurol 14:81-91.

Sherman SM (2016) Thalamus plays a central role in ongoing cortical functioning. Nat Neurosci 19:533-541.

Simons DJ (1978) Response properties of vibrissa units in rat SI somatosensory neocortex. J Neurophysiol 41:798-820.

Sun QQ, Huguenard JR, Prince DA (2005) Reorganization of barrel circuits leads to thalamically-evoked cortical epileptiform activity. Thalamus Relat Syst 3:261-273.

Sun QQ, Huguenard JR, Prince DA (2006) Barrel cortex microcircuits: thalamocortical feedfoward inhibition in spiny stellate cells is mediated by a small number of fast-spiking interneurons. J Neurosci 26:1219-1230.

Swadlow HA (2003) Fast-spike interneurons and feedforward inhibition in awake sensory neocortex. Cereb Cortex 13:25-32.
Swadlow HA, Gusev AG (2002) Receptive-field construction in cortical inhibitory interneurons. Nat Neurosci 5:403-404.

Tottene A, Conti R, Fabbro A, Vecchia D, Shapovalova M, Santello M, van den Maagdenberg AM, Ferrari MD, Pietrobon D (2009) Enhanced excitatory transmission at cortical synapses as the basis for facilitated spreading depression in $\mathrm{Ca}(\mathrm{v}) 2.1$ knockin migraine mice. Neuron 61:762-773.

Tottene A, Urbani A, Pietrobon D (2011) Role of different voltage-gated $\mathrm{Ca}^{2+}$ channels in cortical spreading depression: specific requirement of P/Q-type $\mathrm{Ca}^{2+}$ channels. Channels (Austin) 5:110-114.

Tremblay R, Lee S, Rudy B (2016) GABAergic interneurons in the neocortex: from cellular properties to circuits. Neuron 91:260-292.

Tsai JJ, Norcia AM, Ales JM, Wade AR (2011) Contrast gain control abnormalities in idiopathic generalized epilepsy. Ann Neurol 70:574-582.

van den Maagdenberg AM, Pietrobon D, Pizzorusso T, Kaja S, Broos LA, Cesetti T, van de Ven RC, Tottene A, van der Kaa J, Plomp JJ, Frants RR, Ferrari MD (2004) A Cacnala knockin migraine mouse model with increased susceptibility to cortical spreading depression. Neuron 41:701-710.

Vecchia D, Pietrobon D (2012) Migraine: a disorder of brain excitatoryinhibitory balance? Trends Neurosci 35:507-520.

Vecchia D, Tottene A, van den Maagdenberg AM, Pietrobon D (2014) Mechanism underlying unaltered cortical inhibitory synaptic transmission in contrast with enhanced excitatory transmission in $\mathrm{Ca}_{\mathrm{V}} 2.1$ knockin migraine mice. Neurobiol Dis 69:225-234.

Waldeck RF, Pereda A, Faber DS (2000) Properties and plasticity of pairedpulse depression at a central synapse. J Neurosci 20:5312-5320.

Whitmire CJ, Stanley GB (2016) Rapid sensory adaptation redux: a circuit perspective. Neuron 92:298-315. 